\title{
Afternoon Ascospore Release in Claviceps purpurea Optimizes Perennial Ryegrass Infection
}

Stephen C. Alderman, United States Department of Agriculture-Agricultural Research Service (USDA-ARS) National Forage Seed Production Research Center, Corvallis OR, 97331; Darrin L. Walenta, Oregon State University Union County Extension Service, La Grande 97850; Philip B. Hamm, Department of Botany and Plant Pathology, Oregon State University Hermiston Agricultural Research and Extension Center, Hermiston, OR 97838; Ruth C. Martin, USDA-ARS National Forage Seed Production Research Center; Jeremiah Dung, Department of Botany and Plant Pathology, Oregon State University, Central Oregon Agricultural Research Center, Madras 97741; and Evsey Kosman, Institute for Cereal Crops Improvement, Tel Aviv University, Ramat Aviv, Tel Aviv 69978, Israel

\begin{abstract}
Alderman, S. C., Walenta, D., Hamm, P. B., Martin, R. C., Dung, J., and Kosman, E. 2015. Afternoon ascospore release in Claviceps purpurea optimizes perennial ryegrass infection. Plant Dis. 99:1410-1415.

In Kentucky bluegrass (Poa pratensis), Claviceps purpurea, the causal agent of ergot, typically releases ascospores during the early-morning hours, between about midnight and 10:00 A.M., corresponding to time of flowering, when the unfertilized ovaries are most susceptible to infection. During aeromycology studies of $C$. purpurea in perennial ryegrass (Lolium perenne) in northeastern Oregon during 2008 to 2010 and 2013, a strain of C. purpurea was found that released ascospores in the afternoon, coinciding with flowering in perennial ryegrass. Under controlled environmental conditions, sclerotia from perennial ryegrass and Kentucky bluegrass released spores in the

afternoon and morning, respectively, consistent with timing of spore release under field conditions. Internal transcribed spacer (ITS) sequences of single sclerotial isolates from Kentucky bluegrass and perennial ryegrass were consistent with C. purpurea, although minor variations in ITS sequences among isolates were noted. Differences between Kentucky bluegrass and perennial ryegrass isolates were observed in random amplified polymorphic DNA. Evidence is provided for adaptation of $C$. purpurea to perennial ryegrass by means of delayed spore release that coincides with afternoon flowering in perennial ryegrass.
\end{abstract}

Kentucky bluegrass (Poa pratensis L.) (KBG) and perennial ryegrass (Lolium perenne L.) (PRG) are important seed crops in Oregon. Most of the PRG production is in the Willamette Valley, in western Oregon, although production in eastern Oregon, including the Columbia Basin in Umatilla and Morrow counties, has increased over the past decade to about 1,345 ha in 2013 (http://cropandsoil. oregonstate.edu/system/files/u1473/CRD031314-p2.pdf). KBG production occurs almost entirely in eastern Oregon, including central Oregon near Madras, northeastern Oregon in the Grand Ronde Valley near La Grande, and the Columbia Basin. KBG seed production has declined in the Columbia Basin in recent years to about 1,012 ha (http://cropandsoil.oregonstate.edu/system/files/u1473/CRD031314-p2. pdf) as PRG acreage has increased. Ergot, caused by the floral infecting fungus Claviceps purpurea (Fr.) Tul., is a long-standing problem in KBG production in central and northeastern Oregon (Alderman et al. 1996 1998). Over the past decade, the occurrence and severity of ergot in PRG in the Columbia Basin has increased.

About the time of host flowering in the spring, ascospores of C. purpurea are released from overwintering sclerotia and infect grass ovaries. Conidia are produced on the surface of colonized ovaries and mix with plant sap in what is commonly referred to as the honeydew stage. Conidia can contribute to secondary spread via insects, rain splashing, or mechanical contact. By the time of host seed maturity, most of the infected ovaries have been converted to elongated black sclerotia. C. purpurea has a wide host range, including about 165 species in the United States (Alderman et al. 2004).

Corresponding author: S. C. Alderman; E-mail: aldermas@onid.orst.edu

*The $\boldsymbol{e}$-Xtra logo stands for "electronic extra" and indicates that one supplementary figure is published online.

Accepted for publication 15 March 2015.

http://dx.doi.org/10.1094/PDIS-09-14-0978-RE

This article is in the public domain and not copyrightable. It may be freely reprinted with customary crediting of the source. The American Phytopathological Society, 2015.
Aeromycology studies in KBG indicate that most ascospores are released between late night and early morning, corresponding to flowering in KBG (Alderman 1993; Alderman et al. 2010), with few ascospores airborne in the afternoon. PRG, however, typically flowers in the afternoon. In aeromycology studies of $C$. purpurea in PRG in the Columbia Basin during 2008 (conducted in parallel with a study in KBG; Alderman et al. 2010), two peaks of airborne ascospores of $C$. purpurea occurred: one at night to early morning, typical for $C$. purpurea spore release, and a second in the afternoon. This was unexpected and we are not aware of any other cases of a shift in timing of ascospore release in $C$. purpurea.

The objectives of this study were to (i) determine whether an afternoon release of ascospores of $C$. purpurea in PRG was consistently observed in PRG fields over years and locations, (ii) determine whether the afternoon ascospore release from PRG sclerotia and early-morning ascospore release from KBG sclerotia would occur under controlled environmental conditions, and (iii) determine whether Claviceps isolates collected from PRG and KBG were C. purpurea or different Claviceps spp.

\section{Materials and Methods}

Timing of release of ascospores under field conditions. To determine the peak periods of ascospore release, airborne ascospores were monitored with Burkard 7-day volumetric spore traps. The traps were placed near the center of a 51-ha commercial PRG field planted in 2007, near Hermiston, OR (site 1) from May to July in 2008, 2009, and 2010. A parallel study in KBG near La Grande, OR was previously published (Alderman et al. 2010). In 2010, $5.82 \mathrm{~kg}$ of $C$. purpurea sclerotia (estimated 4.6 million sclerotia), obtained from seed cleaning facilities in Hermiston that cleaned seed from a PRG field, were dispersed by hand over a field plot ( 12 by $37 \mathrm{~m}$ ) of PRG at the Oregon State University Hermiston Agricultural Research and Extension Center (site 2), and a spore trap was placed in the center of the plot. In 2013, a spore trap was placed in a 50-ha commercial PRG field near Hermiston, OR (site 3). At each site, the spore traps were positioned with the orifice approximately $42 \mathrm{~cm}$ above the ground and the air intake was maintained at 10 liters/min. Air intake 
was checked at least once weekly. Spore tapes were prepared, processed, and examined as previously described (Alderman 1993). Spore trap tapes (uncoated Melinex; DuPont) were coated with a thin layer of silicone grease. After 1 week of exposure, each tape was cut into daily segments, and hourly partitions were marked by lightly pressing the edge of a single-edge razor blade to the tape over a template with hours marked. Tapes were stained with aniline blue (Alderman 1993), covered with a cover glass, sealed with Permount (Fisher Scientific), and examined under an Olympus BX50 microscope (Olympus Corp.) at $\times 100$ or $\times 200$.

To estimate the time of flowering, the time of pollen release was determined. The number of pollen grains and $C$. purpurea ascospores on spore tapes were counted for each hour and then totaled between 12:00 A.M. and 11:59 P.M. to establish daily counts. Ascospore counts for each site and year were expressed as a percentage of total ascospores trapped at the site.

Reference slides of known $C$. purpurea ascospores were prepared by placing two sclerotia with mature capitula in each of four petri plates lined with moist tissue paper and attaching prepared spore trap tape onto the inside of each petri plate lid. The sclerotia were collected from KBG seed production fields and germinated in each of four pots with a commercial potting mix (Sunshine SB40; Sun Grow Horticulture) in a growth chamber. Reference slides of pollen grains were prepared by shaking flowering seed heads from at least three plants of KBG or PRG onto coated Melinex tape segments. The source plants for KBG or PRG pollen were grown from seed in square pots ( $10 \mathrm{~cm}$ wide, one plant per pot) containing commercial potting mix under greenhouse conditions. Slides were stained with aniline blue and processed in the same manner as the spore trap tapes. Reference slides were referred to for morphological details when identifying ascospores or pollen on spore tapes. Identification of grass pollen to species was not attempted.

Timing of ascospore release under controlled environmental conditions. To determine whether the diurnal periodicity of ascospore release observed under field conditions would occur under controlled environmental conditions, ascospore release from C. purpurea sclerotia collected from PRG and KBG was monitored in growth chambers. The experiment was arranged as a two-way factorial completely randomized design (CRD), with sclerotia source (KBG or PRG) and time period (morning or afternoon) as fixed effects. All treatment combinations were replicated four times and the experiment was repeated under the same conditions in a different growth chamber. Mature sclerotia from PRG and KBG were obtained from commercial seed cleaning facilities near Hermiston. The seed cleaning facilities processed seed of PRG and KBG separately by seed lot to ensure that the sclerotia collected were from a single host and seed lot. Sclerotia were surface sterilized in $10 \%$ bleach for $1 \mathrm{~min}$ and rinsed with sterile deionized water $\left(\mathrm{sdH}_{2} \mathrm{O}\right)$. Sclerotia were incubated without light at 5 to $6^{\circ} \mathrm{C}$ for 6 weeks in sterilized soil moistened with $\mathrm{sdH}_{2} \mathrm{O}$, followed by incubation at 15 to $16^{\circ} \mathrm{C}$ under $15 \mathrm{~h}$ of light and $9 \mathrm{~h}$ of darkness for 2 to 4 weeks to induce sclerotia germination and the production of capitula. A single sclerotium was placed in the center of each of four petri plates containing moistened sterile soil. When necessary, capitula were removed from sclerotia so that each sclerotium possessed only one capitulum. Spore production for each capitulum was verified using a dissecting microscope. Melinex tape coated with silicone grease was placed on the lid of the petri plate. Spores were trapped in the morning (between 12:00 and 6:00 A.M.) and afternoon (between 12:00 and 6:00 P.M.). Lids and Melinex tape were replaced every hour at the beginning of each hour. A section of Melinex tape ( 22 by $22 \mathrm{~mm}$ ) was removed from the petri plate lid and stained with aniline blue. Tape sections were initially viewed at $\times 200$ magnification and spores were counted at $\times 400$ magnification in five representative views that were each $200 \mu \mathrm{m}$ in diameter. The number of spores for each hour was determined and totaled for each 6-h morning or afternoon period.

Spore counts were converted to the percentage of total spores captured and subjected to arcsine transformation to satisfy assumptions for analysis of variance (ANOVA). ANOVA was conducted using
PROC MIXED in SAS (version 9.3; SAS Institute). Data were analyzed as a two-way factorial CRD, with sclerotia source and time period as fixed effects and trial as a random effect. A $t$ test was performed using PROC MIXED and the LSMEANS statement in SAS to compare the percentage of total spores from the morning and afternoon time periods for each host source.

Fungal isolates and DNA extraction. DNA was isolated from fungal isolates collected from PRG and KBG fields to facilitate molecular analyses of the population structure of Claviceps from different host species. In June 2010, C. purpurea sclerotia were collected from a commercial PRG field near Hermiston, OR (field 1) and from two KBG fields near La Grande, OR (fields 2 and 3). From each site, 10 sclerotia were surface sterilized by dipping in $95 \%$ ethanol for $30 \mathrm{~s}$, soaking in $10 \%$ bleach solution for $1 \mathrm{~min}$, and rinsing in sterile water for $15 \mathrm{~s}$. Sclerotia were bisected with a flame-sterilized blade and placed on the surface of water agar in $8.5-\mathrm{cm}$-diameter petri plates (2 to 3 sclerotia per plate). Isolates were established on Difco potato dextrose agar. For molecular analyses, a 5-mm mycelial plug from each of the 30 isolates was transferred to a 125 -ml flask containing $50 \mathrm{ml}$ of Difco potato dextrose broth and cultured at room temperature on a horizontal shaker with slow rotation. One KBG isolate was lost, resulting in 29 total isolates (19 KBG and 10 PRG isolates). After about 3 weeks, fungal mycelia were collected on a filter paper in a Buchner funnel and then rinsed with $100 \mathrm{ml}$ of $\mathrm{sdH}_{2} \mathrm{O}$ in the Buchner funnel under vacuum. Mycelia were removed from the filter paper and freeze dried. DNA was extracted using the FastDNA Kit from MP Biomedicals, LLC. Approximately $25 \mathrm{mg}$ of freezedried sample was placed in Lysing Matrix C tubes (MP Biomedicals, LLC) and pulverized for $40 \mathrm{~s}$ at a setting of 6 using a FastPrep FP120 instrument (BIO101 ThermoSavant). After adding $1 \mathrm{ml}$ of CLS-Y (Cell Lysis/DNA solution Y) to each tube, the samples were mixed by inversion and homogenized twice (setting 6 for $45 \mathrm{~s}$ ) in the FastPrep 120 instrument. Samples were incubated for $2 \mathrm{~h}$ at room temperature and then centrifuged at $12,000 \times g$ for $10 \mathrm{~min}$. The resulting supernatant was processed according to kit instructions. The isolated DNA was further purified by chloroform extraction, precipitated with ammonium acetate and isopropanol, and washed with $70 \%$ ethanol following standard protocols (Sambrook et al. 1989). DNA concentration was determined using a NanoDrop 2000 (Thermo Fisher Scientific). All samples were diluted to a concentration of $20 \mathrm{ng} / \mu \mathrm{l}$ for subsequent polymerase chain reaction (PCR).

PCR and sequencing of the internal transcribed spacer region. PCR was utilized to amplify the internal transcribed spacer (ITS) region to characterize the Claviceps populations from different host species. Primers for amplifying the ITS region were ITS1: TCCGTAGGTGAACCTGCGG and ITS4: TCCTCCGCTTATTGATATGC (White et al. 1990). The PCR reaction mix consisted of $1 \times$ PrimeSTAR buffer, $0.2 \mu \mathrm{M}$ each dNTP, $0.3 \mu \mathrm{M}$ primers, $20 \mathrm{ng}$ of DNA, and $1.25 \mathrm{U}$ of PrimeSTAR HS DNA Polymerase (Takara) in a final volume of $50 \mu \mathrm{l}$. PCR was performed on an MJ PTC 200 thermocycler (Bio-Rad) with the following program: $98^{\circ} \mathrm{C}$ for $30 \mathrm{~s} ; 30$ cycles of $98^{\circ} \mathrm{C}$ for $10 \mathrm{~s}$, $55^{\circ} \mathrm{C}$ for $5 \mathrm{~s}$, and $72^{\circ} \mathrm{C}$ for $1 \mathrm{~min}$; followed by a 10 -min extension at $72^{\circ} \mathrm{C}$. The mixture was kept at $4{ }^{\circ} \mathrm{C}$ until removal from the instrument. PCR products were separated on a $1.2 \%$ agarose Tris-acetateEDTA gel and purified using a Qiagen QIAEX Gel Extraction Kit (Qiagen). Products were sequenced in both directions on an ABI Prism 3730 Genetic Analyzer at the Center for Genome Research and Biocomputing at Oregon State University. PCR resulted in a product of approximately $580 \mathrm{bp}$, including the ITS1, 5.8S, and ITS2 region of the ribosomal cassette. Sequences were aligned using ClustalW (Larkin et al. 2007). Phylogenetic and molecular evolutionary analyses were conducted using MEGA version 5 (Tamura et al. 2011).

Random amplified polymorphic DNA analysis. Random amplified polymorphic DNA (RAPD) was used to determine the relationship between populations of Claviceps from different host species. Primer 257 (CGTGATGTCAGTGATGC) (Pažoutová et al. 2000) was utilized for RAPD analyses. Each reaction contained dNTPs at a concentration of $200 \mu \mathrm{M}, 12.5 \mathrm{pM}$ primer, $1 \times$ ExTaq PCR buffer (Takara), $0.1 \mu \mathrm{l}$ of dimethyl sulfoxide, $25 \mathrm{ng}$ of DNA, and $0.125 \mu \mathrm{l}$ of ExTaq in a $25-\mu 1$ reaction. The cycling conditions were as follows: 
$94^{\circ} \mathrm{C}$ for $4 \mathrm{~min} ; 45$ cycles of $94^{\circ} \mathrm{C}$ for $20 \mathrm{~s}, 38^{\circ} \mathrm{C}$ for $1 \mathrm{~min}$, and $72^{\circ} \mathrm{C}$ for $2 \mathrm{~min}$; followed by $72{ }^{\circ} \mathrm{C}$ for $6 \mathrm{~min}$ and a $4^{\circ} \mathrm{C}$ hold until removal from the thermocycler. The products were separated on a $2 \%$ agarose gel in Tris-borate-EDTA buffer at $75 \mathrm{~V}$ for $12 \mathrm{~h}$, stained with ethidium bromide, and visualized with a UVP gel documentation system (UVP). The major RAPD bands (approximately 540, 720, 750, 780, $900,1,400$, and $1,700 \mathrm{bp}$ ) were scored as 1 (present) or 0 (absent) for each individual, and pairwise dissimilarities between the RAPD patterns of isolates were measured by the simple mismatch $(m)$ and Jaccard $(j)$ coefficients, as was recommended for dominant markers by Kosman and Leonard (2005). Relationships between populations were estimated using the Kosman distance $\left(K B_{m}\right.$ and $\left.K B_{j}\right)$ with regard to the simple mismatch and Jaccard dissimilarity, respectively (Kosman 1996; Kosman and Leonard 2007). Differentiation among populations was assessed with the permutation test on the basis of the Kosman diversity $\left(K W_{m}\right.$ and $K W_{j}$ ) with regard to the simple mismatch and Jaccard dissimilarity, respectively (Kosman 2014; Kosman et al. 2014). All calculations were performed with the Virulence Analysis Tool software and its extension (Schachtel et al. 2012).

\section{Results}

Timing and release of ascospores under field conditions. In 2008 to 2010 and 2013, spores were observed in traps as early as 1 May and as late as 25 June, depending on year (Fig. 1). In each year and at each site, two peaks in percent total ascospores trapped in the PRG fields were observed, with peak occurrences between 12:00 and 6:00 A.M. and between 12:00 and 6:00 P.M. (Fig. 2). A more pronounced afternoon spore peak was observed at the research station site (site 2), where sclerotia from PRG were distributed in the plot (Fig. 2). Peak pollen counts (Fig. 3) corresponded to field observations of peak flowering. In a previously published study of spore release in KBG fields in northeast Oregon (the Grand Ronde Valley near La Grande, OR), and conducted at the same time and in parallel

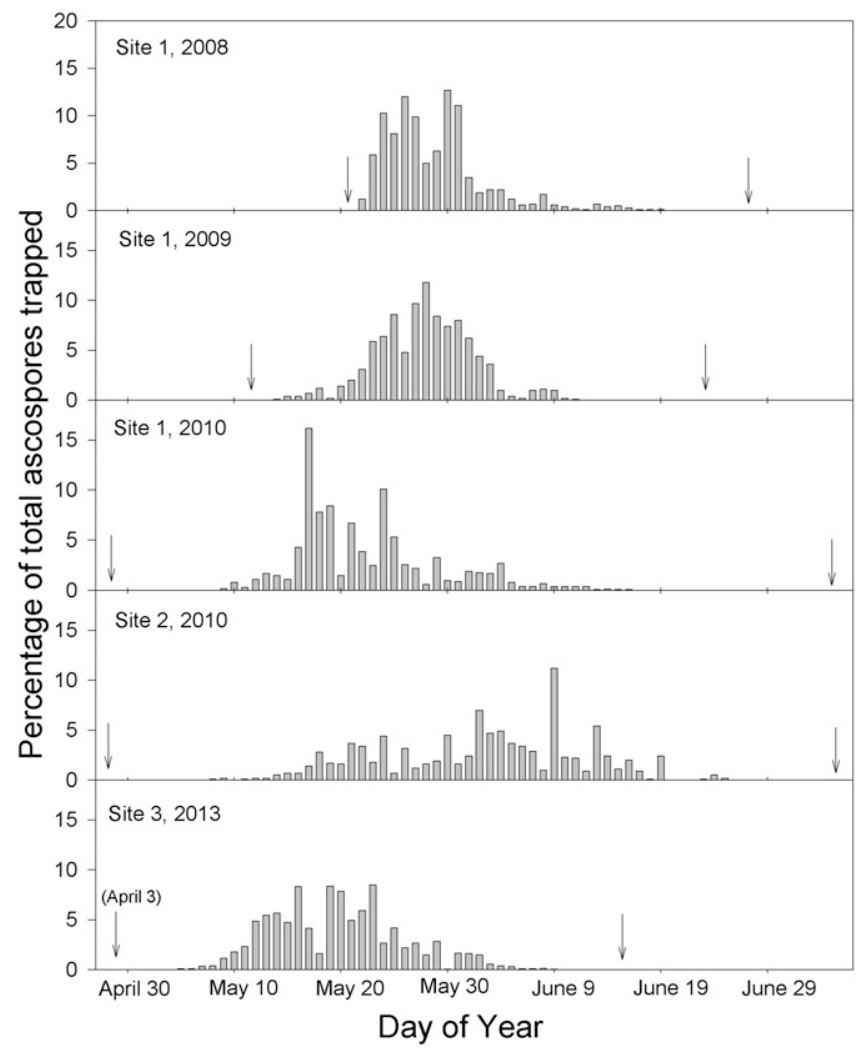

Fig. 1. Percentage of total ascospores trapped in a commercial perennial ryegrass field near Hermiston (site 1) during 2008 to 2010, a perennial ryegrass field plot at the Hermiston Agricultural Research and Extension Center (site 2) during 2010, and a commercial perennial ryegrass field near Hermiston during 2013 (site 3). Arrows indicate the start and end of spore trapping period.

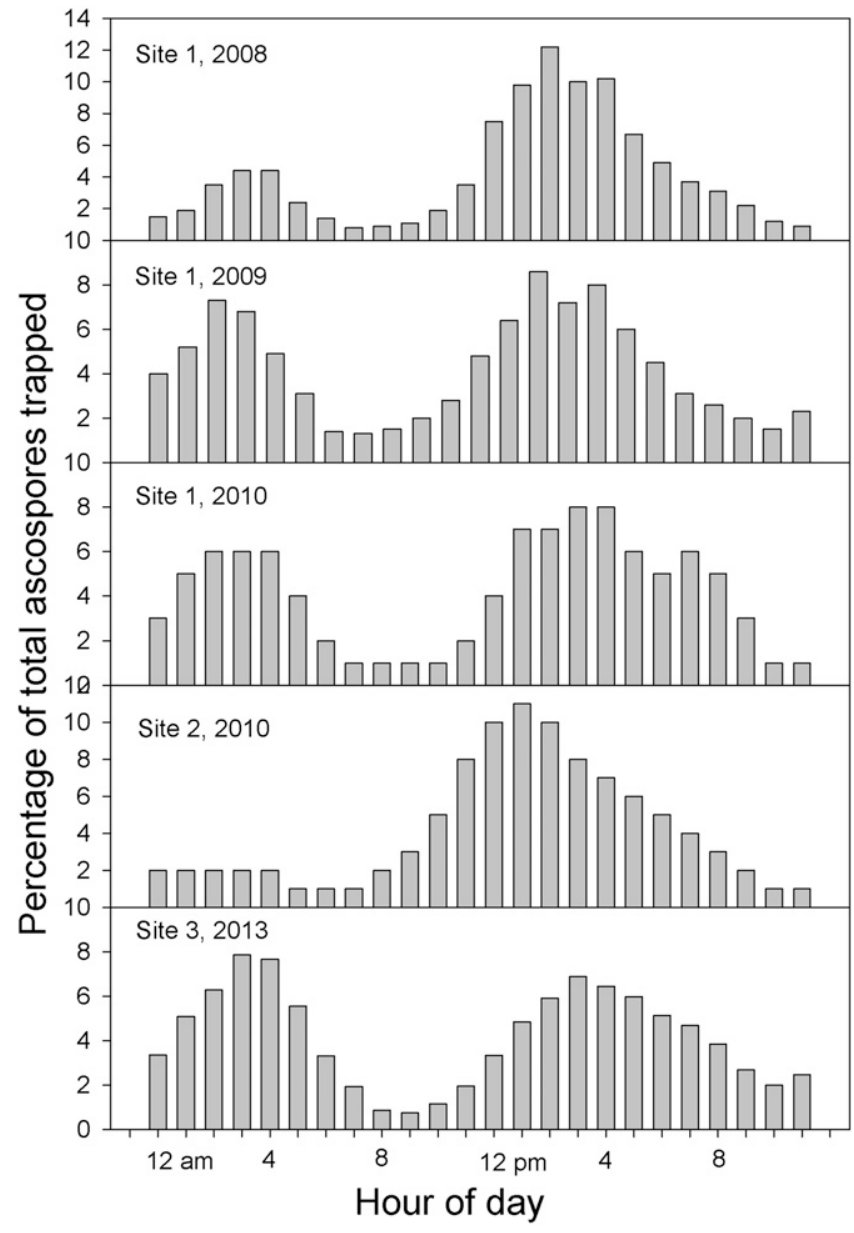

Fig. 2. Percentage of total ascospores trapped during each hour of day in a commercial perennial ryegrass field near Hermiston (site 1) during 2008 to 2010, a field plot of tall fescue at the Hermiston Agricultural Research and Extension Center (site 2) during 2010, and a commercial perennial ryegrass field near Hermiston during 2013 (site 3).

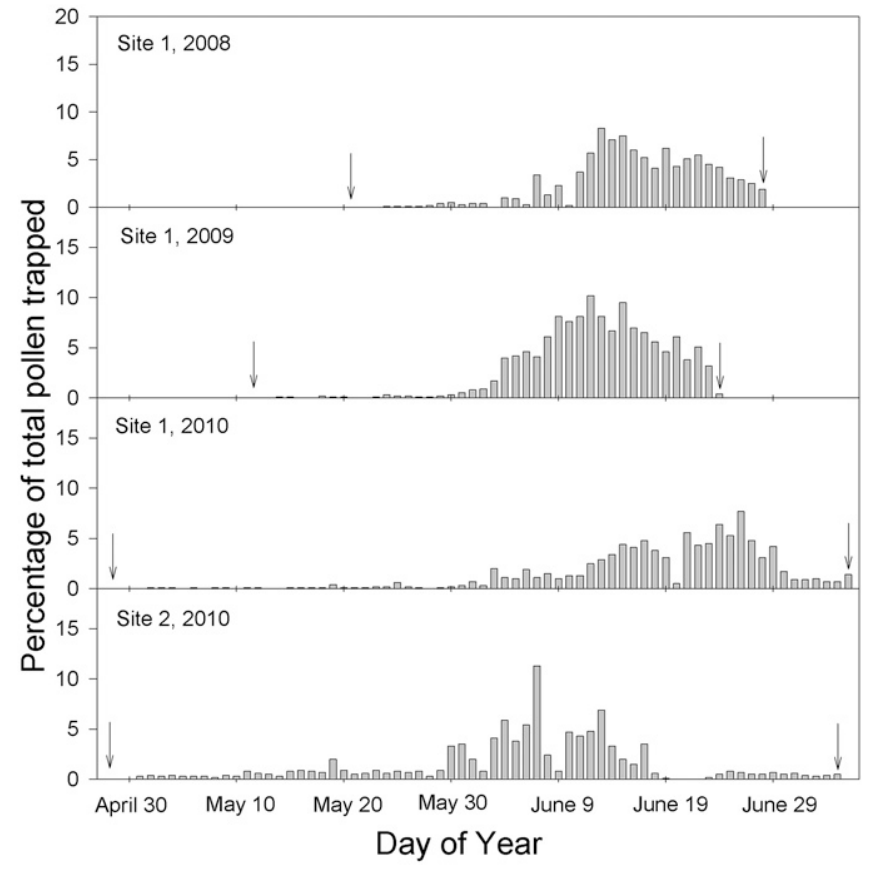

Fig. 3. Percentage of total grass pollen trapped in a commercial perennial ryegrass field near Hermiston (site 1) during 2008 to 2010 and the Hermiston Agricultural Research and Extension Center (site 2) during 2010. Pollen was not counted in 2013. 
with the current study, most ascospores were trapped between 1:00 and 8:00 A.M., with few to no spores trapped between 12:00 and 5:00 P.M. (Alderman et al. 2010).

Timing of ascospore release under controlled environmental conditions. Differences in the timing of spore release were observed for sclerotia collected from PRG (Fig. 4) and KBG (Fig. 5) in both trials. Based on ANOVA, there was no significant difference between experimental trials $(P>0.05)$; therefore, data were combined for analyses (Table 1). Significant interactions between sclerotia source (KBG versus PRG) and time of day (morning versus afternoon) were observed $(P<0.0001)$. Sclerotia from KBG released $85 \%$ of total spores in the morning and $15 \%$ of total spores in the afternoon. Conversely, sclerotia from PRG released 28 and $72 \%$ of spores during the morning and afternoon, respectively. Significant differences in the percentage of total spores captured during morning and afternoon were observed for both host sources $(P<0.0001)$. In many cases, all KBG spores were counted on samples collected during the morning hours. Overall, more spores were captured from sclerotia collected from PRG $(3,447)$ than from KBG $(1,788)$.

DNA sequence analysis. PCR reactions using the ITS1 and ITS4 primers resulted in a product of approximately $580 \mathrm{bp}$, including the ITS1, 5.8s, and ITS2 region of the ribosomal cassette. All sequences were submitted to GenBank database (accession numbers KM624484 to KM624512). A BLAST search revealed that all of the ITS sequences were most closely related to $C$. purpurea. Sequences were compared with other Claviceps spp. available in the GenBank database. Based on the sequencing of the ITS region, the 29 isolates all clustered with $C$. purpurea and were distinct from

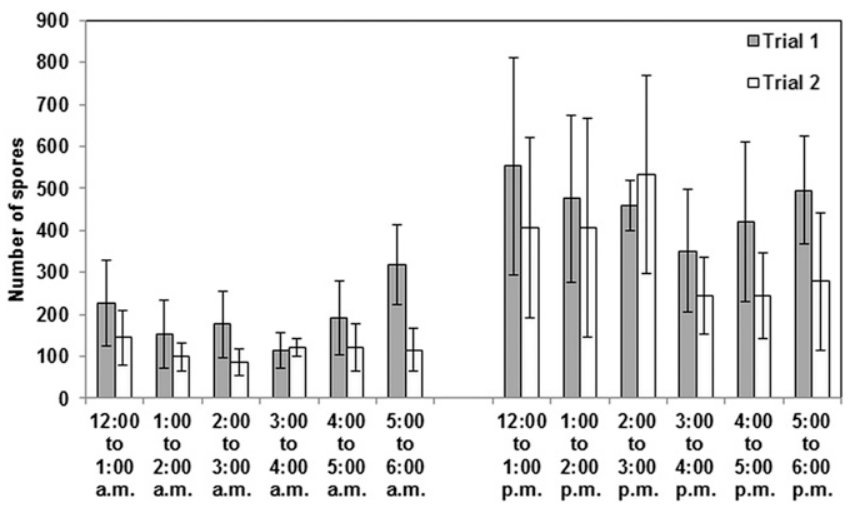

Fig. 4. Number of ergot ascospores originating from sclerotia from perennial ryegrass released hourly between midnight and 6 A.M. and between noon and 6 P.M. by capitula produced by sclerotia collected from perennial ryegrass. Error bars represent standard deviations.

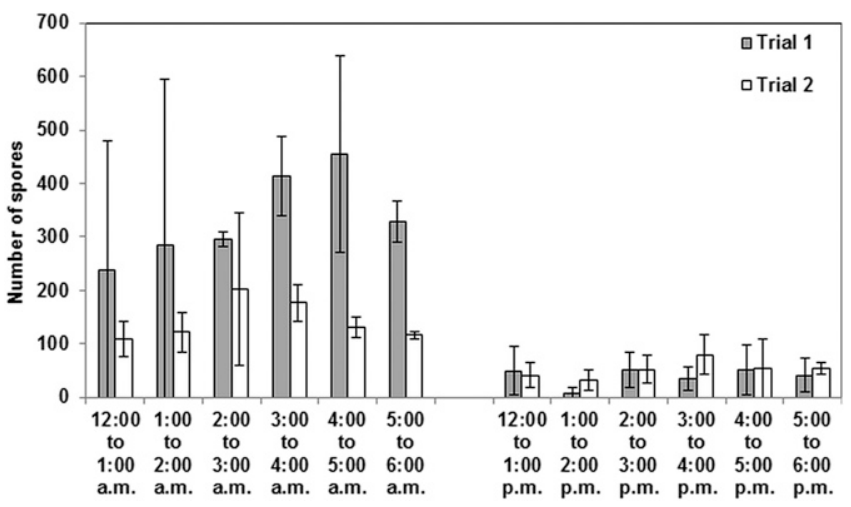

Fig. 5. Number of ergot ascospores originating from Kentucky bluegrass released hourly between midnight and 6 A.M. and between noon and 6 P.M. by capitula produced by sclerotia collected from Kentucky bluegrass. Error bars represent standard deviations. other Claviceps spp. (Fig. 6). Further phylogenetic analysis using Phylogeny.fr (Dereeper et al. 2008) and examining only the isolates from this study separated the isolates into four main groups, with one isolate on its own branch (Supplementary Fig. S1). The largest groups included isolates from each of the three fields. The sequences

Table 1. Number and percentage of total ergot ascospores collected in the morning (12:00 to 6:00 a.m.) and afternoon (12:00 to 6:00 p.m.) hours from germinated ergot sclerotia obtained from Kentucky bluegrass and perennial ryegrass

\begin{tabular}{lrrr}
\hline Host & Morning & Afternoon & $\boldsymbol{P}$ value $^{\mathbf{a}}$ \\
\hline Kentucky bluegrass & $1,520(85 \%)$ & $268(15 \%)$ & $<0.0001$ \\
Perennial ryegrass & $968(28 \%)$ & $2,479(72 \%)$ & $<0.0001$ \\
\hline
\end{tabular}

a $P$ value obtained from $t$ test using arcsine-transformed percentage data pooled from two experimental runs.

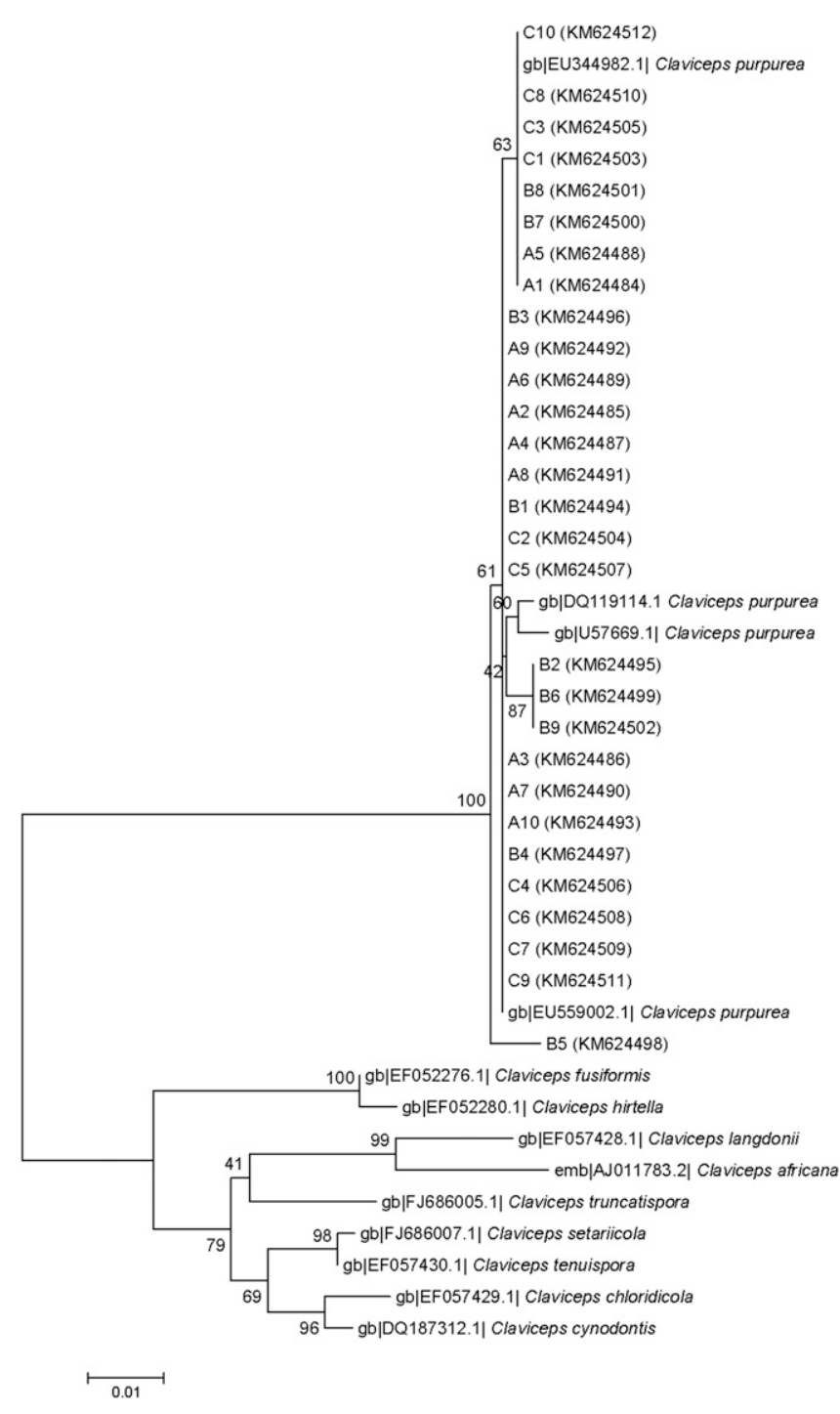

Fig. 6. Phylogenetic tree depicting the relationship of field isolates examined in this study, based on the partial sequence of the internal transcribed spacer (ITS) region using primers ITS1 and ITS4 (White et al. 1990). Sequences were aligned using ClustalW and analyzed using the MEGA (Tamura et al. 2011) neighbor-joining tree program using the bootstrap method (1,000 bootstrap replications) and maximum composite likelihood model. The bar length represents 7 nucleotide differences/1,000. A1 to A10: sclerotia from perennial ryegrass field (field 1); B1 to B9: sclerotia from Kentucky bluegrass field (field 2); and $\mathrm{C} 1$ to $\mathrm{C} 10$ : sclerotia from Kentucky bluegrass field (field 3). GenBank accession numbers for sequences obtained in this study are in parentheses after isolate number. 
of the isolates were very similar, with most groups varying by only a few nucleotides.

RAPD analysis. The RAPD profiles of isolates from different fields had a common amplicon of approximately 540 bp (Fig. 7), which has been reported as a species-specific band for $C$. purpurea (Pažoutová and Tudzynski 1999) when using primer 257. RAPD profiles of 10 isolates from a PRG field (field 1) (A1 through A10; Fig. 7, lanes 1 to 10) revealed four isolates (A5, A6, A7, and A9; Fig. 7, lanes 5 to 7 and 9) with similar banding patterns. Isolates A 2 and A10 shared a unique amplicon banding pattern (Fig. 7, lanes 2 and 10). Isolates from KBG (field 2, B1 to B9; Fig. 7, lanes 11 to 19) all had unique banding patterns but were still consistent with C. purpurea. Banding patterns of isolates from $\mathrm{KBG}$ (field 3, C1 to $\mathrm{C} 10$; Fig. 7, lanes 20 to 29 ) revealed several isolates with similar banding patterns (C4 to C7, Fig. 7, lanes 23 to 26; C3 and C8, Fig. 7, lanes 22 and 27; and $\mathrm{C} 2$ and $\mathrm{C} 9$, Fig. 7, lanes 21 and 28) while others were unique within the group (C1 and C10, Fig. 7, lanes 20 and 29). Although this is only a preliminary study and the sample size is relatively small, methods of diversity analysis support the hypothesis that there is a difference between the pathogen populations from KBG and PRG fields. Results obtained with the simple mismatch coefficient were very similar to those with the Jaccard dissimilarity; therefore, only the former ones are reported here. The populations from the PRG field and KBG fields were much more distant than those from two KBG fields, with $K B_{m}$ values of 0.43 between the PRG and pooled KBG populations and 0.25 between the two KBG populations. In addition, differentiation among the PRG and pooled KBG populations obtained with 500 permutations on the basis of $K W_{m}$ diversity was nearly absolute, while hypothesis of identity between populations from two different KBG fields was not rejected.

\section{Discussion}

Previous research reported a diurnal periodicity of early-morning ascospore release in KBG fields in western and northeastern Oregon (Alderman 1993; Alderman et al. 2010). In this multiyear study, the majority of $C$. purpurea ascospores were observed during the afternoon hours in four PRG fields located in Umatilla County, Oregon. Under controlled conditions in growth chambers, the majority of ascospores produced by sclerotia collected from PRG were observed during the afternoon hours, whereas the majority of ascospores produced by sclerotia from KBG were observed during the morning hours. The former observation is in agreement with previous studies conducted over several years and at several locations in the Willamette Valley and Union County of Oregon (Alderman 1993; Alderman et al. 2010). The similar results observed in the field and under common, controlled growth chamber conditions suggest that sclerotia from PRG and KBG have adapted to release ascospores at different times of the day.

Variability in genetics of $C$. purpurea is well recognized (Tudzynski 1999), and this likely has contributed to the adaptation of $C$. purpurea to

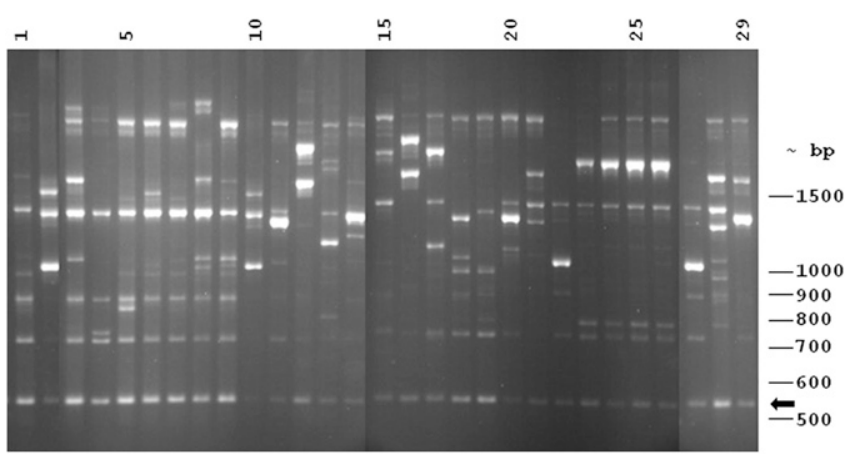

Fig. 7. Random amplified polymorphic DNA profiles of isolates using primer 257 (Pažoutová et al. 2000). Lanes 1 to $10, A 1$ to $A 10$ from perennial ryegrass, field 1 ; lanes 11 to 19, B1 to B9 from Kentucky bluegrass field, field 2; and lanes 20 to 29, $\mathrm{C} 1$ to $\mathrm{C} 10$ from Kentucky bluegrass field, field 3 . Arrow indicates the approximately 540-bp amplicon specific for Claviceps purpurea. a wide range of environments (Pažoutová et al. 2000). However, a change in the time of day of ascospore release is unique and unexpected. Spore release in fungi is typically in response to environmental conditions, especially moisture-related conditions such precipitation events and humidity levels (Ingold 1971; Lacey 1996). The high frequency of irrigation (as often as every $18 \mathrm{~h}$ ) in PRG fields in the Columbia Basin likely provides environmental conditions favorable for ascospore release in the afternoon, thus providing conditions that would support a shift to afternoon ascospore release in $C$. purpurea.

Afternoon flowering in PRG, which is the time of day when the host is most receptive to infection, may have provided a selective advantage for strains of $C$. purpurea with a delayed spore release. The stigma is the primary means by which $C$. purpurea infects ovaries (Luttrell 1980); therefore, timing of stigma emergence and longevity play an important role in host susceptibility. Ascospores released in the evening or early morning would tend to be blown from the field or land on nonsusceptible host parts, whereas spores released in the afternoon would have a greater probability of successful infection. Timing of pollen release also affects infection, because stigmas from fertilized ovaries wither after host fertilization and are no longer receptive for infection (Campbell and Tyner 1959; Cunfer et al. 1975; Darlington and Mathre 1976). Cool, wet environmental conditions and irrigation during flowering which could interfere with successful pollination and fertilization would also extend the period of host susceptibility to $C$. purpurea.

Although incidence of ergot has steadily increased over the last 10 to 15 years from the first plants of PRG in the Columbia Basin, there is no evidence of increasing levels of ergot in the Willamette Valley in western Oregon, where the majority of PRG is grown. Soil conditions in the Willamette Valley during flowering in PRG are typically dry and fields are not irrigated. Dry soil conditions are unfavorable for the germination of $C$. purpurea sclerotia and production of capitula. Additional studies will be needed to determine whether adjustments could be made to the timing and duration of irrigation in center-pivot PRG fields to reduce favorability of afternoon ascospore release. This option may not be possible in the Columbia Basin, where frequent watering is needed to maintain adequate moisture for crop production due to high transpiration rates and fastdraining sandy soils. However, adjusting irrigation schedules for ergot control may be possible in central Oregon or the Grand Ronde Valley, where soils are heavier and irrigation is less frequent.

Previous studies indicated that some cultivars can escape the peak of spore release by flowering later in the season. However, given the capacity of $C$. purpurea to adapt to host factors such as timing of flowering, it is not clear if later-flowering cultivars would place selection pressure on $C$. purpurea for strains that germinate later in the spring. However, cultivars that flower earlier or later than peak ascospore release could be a component of an integrated ergot management strategy.

Previous studies have indicated a high level of genetic variability in C. purpurea (Tudzynski 1999). Our results demonstrated similar variability in ITS sequences and in RAPD profiles among isolates of $C$. purpurea. Although some isolates differed among the three fields, phylogenetic analysis based on the ITS sequences revealed that there were also isolates common to the fields. Development of single-nucleotide polymorphism markers (either TaqMan or High-Resolution Melting analyses) at sites 183, 368, and 415 could effectively differentiate most groups and could be used as a tool to differentiate various isolates in the future. Analysis of RAPD markers from this limited population indicate that there may be increased diversity in Claviceps populations obtained from different host species compared with the diversity obtained from fields of the same species. However, this is a very limited population and additional studies with larger populations from a greater number of fields and locations will be required to determine whether $C$. purpurea strains associated with specific hosts or with timing of spore release can be identified using additional markers. More research is needed to characterize differences among $C$. purpurea populations in the Willamette Valley, Union County, and Umatilla County and to better understand 
the population structure of $C$. purpurea within and among PRG and KBG seed production fields.

\section{Acknowledgment}

We thank V. (Sagar) Sathuvalli for his help in performing the RAPD and in the analysis of the ITS sequence data.

\section{Literature Cited}

Alderman, S. C. 1993 . Aerobiology of Claviceps purpurea in Kentucky bluegrass. Plant Dis. 77:1045-1049.

Alderman, S. C., Coats, D. D., and Crowe, F. J. 1996. Impact of ergot on Kentucky bluegrass grown for seed in northeastern Oregon. Plant Dis. 80:853-855.

Alderman, S. C., Coats, D. D., Crowe, F. J., and Butler, M. D. 1998. Occurrence and distribution of ergot and estimates of seed loss in Kentucky bluegrass grown for seed in central Oregon. Plant Dis. 82:89-93.

Alderman, S. C., Halse, R. R., and White, J. F. 2004. A reevaluation of the host range and geographical distribution of Claviceps species in the United States. Plant Dis. 88:63-81.

Alderman, S. C., Walenta, D. L., and Hamm, P. B. 2010. Timing of occurrence of Claviceps purpurea ascospores in northeastern Oregon. Online publication. Plant Health Prog. doi:10.1094/PHP-2010-1123-01-RS.

Campbell, W. P., and Tyner, L. E. 1959. Comparison of degree and duration of susceptibility of barley and true loose smut. Phytopathology 49:348-349.

Cunfer, B., Mathre, D. E., and Hockett, E. A. 1975. Factors influencing the susceptibility of male sterile barley to ergot. Crop Sci. 15:194-196.

Darlington, L. C., and Mathre, D. E. 1976. Resistance of male sterile wheat to ergot as related to pollination and host genotype. Crop Sci. 16:728-730.

Dereeper A., Guignon V., Blanc G., Audic S., Buffet S., Chevenet F., Dufayard J.-F., Guindon S., Lefort V., Lescot M., Claverie J.-M., and Gascuel O. 2008. Phylogeny.fr: Robust phylogenetic analysis for the non-specialist. Nucleic Acids Res. 36 (Suppl. 2):W465-W469.

Ingold, C. T. 1971. Fungal Spores, Their Liberation and Dispersal. Claredon Press, Oxford.

Kosman, E. 1996. Difference and diversity of plant pathogen populations: A new approach for measuring. Phytopathology 86:1152-1155.

Kosman, E. 2014. Measuring diversity: From individuals to populations. Eur. J. Plant Pathol. 138:467-486.
Kosman, E., Ben-Yehuda, P., and Manisterski, J. 2014. Diversity of virulence phenotypes among annual populations of wheat leaf rust in Israel from 1993 to 2008. Plant Pathol. 63:563-571.

Kosman, E., and Leonard, K. J. 2005. Similarity coefficients for molecular markers in studies of genetic relationships between individuals for haploid, diploid, and polyploid species. Mol. Ecol. 14:415-424.

Kosman, E., and Leonard, K. J. 2007. Conceptual analysis of methods applied to assessment of diversity within and distance between populations with asexual or mixed mode of reproduction. New Phytol. 174:683-696.

Lacey, J. 1996. Spore dispersal - its role in ecology and disease: The British contribution to fungal aerobiology. Mycol. Res. 100:641-660.

Larkin, M. A., Blackshields, G., Brown, N. P., Chenna, R., McGettigan, P. A., McWilliam, H., Valentin, F., Wallace, I. M., Wilm, A., Lopez, R., Thompson, J. D., Gibson, T. J., and Higgins, D. G. 2007. ClustalW and ClustalX version 2.0 Bioinformatics 23:2947-2948.

Luttrell, E. S. 1980. Host-parasite relationship and development of the ergot sclerotium in Claviceps purpurea. Can. J. Bot. 58:942-958.

Pažoutová, S., Olsovska, J., Linka, M., Kolinska, R., and Flieger, M. 2000. Chemoraces and habitat specialization of Claviceps purpurea populations. Appl. Environ. Microbiol. 66:5419-5425.

Pažoutová, S., and Tudzynski, P. 1999. Claviceps sp. PRL 1980 (ATCC 26245), 59 and Pepty 695/ch-I: Their true story. Mycol. Res. 103:1044-1048.

Sambrook, J., Fritsch, E. F., and Maniatis, T. 1989. Molecular Cloning: A Laboratory Manual, 2nd ed. Cold Spring Harbor Laboratory Press, Cold Spring Harbor, NY.

Schachtel, G. A., Dinoor, A., Herrmann, A., and Kosman, E. 2012. Comprehensive evaluation of virulence and resistance data: A new analysis tool. Plant Dis. 96: 1060-1063.

Tamura, K., Peterson, D., Peterson, N., Stecher, G., Nei, M., and Kumar, S. 2011 MEGA5: Molecular evolutionary genetics analysis using maximum likelihood, evolutionary distance, and maximum parsimony methods. Mol. Biol. Evol. 28: 2731-2739.

Tudzynski, P. 1999. Genetics of Claviceps purpurea. Pages 79-93 in: Ergot, The Genus Claviceps. V. Kren and L. Cvak, eds. Harwood Academic Publishers, Australia.

White, T. J., Bruns, T. D., Lee, S., and Taylor, J. 1990. Amplification and direct sequencing of fungal ribosomal RNA genes for phylogenetics. Pages 315-322 in: PCR Protocols: A Guide to Methods and Applications. M. A Innis, D. H. Gelfand, J. J. Sninsky, and T. J. White, eds. Academic Press, San Diego, CA. 